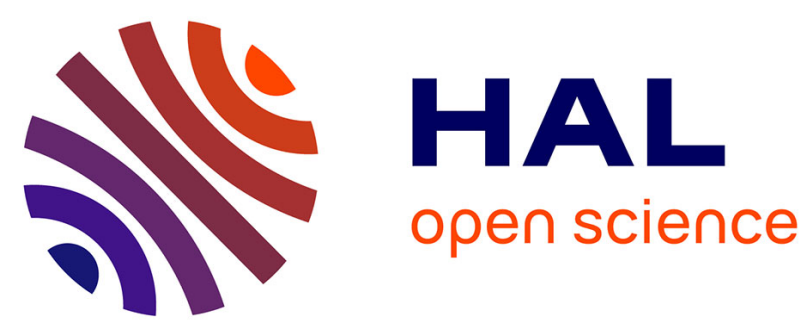

\title{
Uterine motor alterations and estrous cycle disturbances associated with colonic inflammation in the rat
}

\author{
Eric Houdeau, Muriel Larauche, Regine Monnerie, Lionel Bueno, Jean
}

Fioramonti

\section{- To cite this version:}

Eric Houdeau, Muriel Larauche, Regine Monnerie, Lionel Bueno, Jean Fioramonti. Uterine motor alterations and estrous cycle disturbances associated with colonic inflammation in the rat. AJP - Regulatory, Integrative and Comparative Physiology, 2005, 288 (3), pp.R630-R637. 10.1152/ajpregu.00482.2004 . hal-02681734

\section{HAL Id: hal-02681734 \\ https://hal.inrae.fr/hal-02681734}

Submitted on 31 May 2020

HAL is a multi-disciplinary open access archive for the deposit and dissemination of scientific research documents, whether they are published or not. The documents may come from teaching and research institutions in France or abroad, or from public or private research centers.
L'archive ouverte pluridisciplinaire HAL, est destinée au dépôt et à la diffusion de documents scientifiques de niveau recherche, publiés ou non, émanant des établissements d'enseignement et de recherche français ou étrangers, des laboratoires publics ou privés. 


\section{Eric Houdeau, Muriel Larauche, Régine Monnerie, Lionel Bueno and Jean}

Fioramonti

Am J Physiol Regulatory Integrative Comp Physiol 288:630-637, 2005. First published Nov 11, 2004; doi:10.1152/ajpregu.00482.2004

You might find this additional information useful...

This article cites 50 articles, 18 of which you can access free at:

http://ajpregu.physiology.org/cgi/content/full/288/3/R630\#BIBL

This article has been cited by 1 other HighWire hosted article:

Changes in urinary bladder smooth muscle function in response to colonic inflammation

R. Noronha, H. Akbarali, A. Malykhina, R. D. Foreman and B. Greenwood-Van Meerveld Am J Physiol Renal Physiol, November 1, 2007; 293 (5): F1461-F1467.

[Abstract] [Full Text] [PDF]

Updated information and services including high-resolution figures, can be found at:

http://ajpregu.physiology.org/cgi/content/full/288/3/R630

Additional material and information about American Journal of Physiology - Regulatory, Integrative and Comparative Physiology can be found at:

http://www.the-aps.org/publications/ajpregu

This information is current as of September 7, 2010 .

The American Journal of Physiology - Regulatory, Integrative and Comparative Physiology publishes original investigations that illuminate normal or abnormal regulation and integration of physiological mechanisms at all levels of biological organization, ranging from molecules to humans, including clinical investigations. It is published 12 times a year (monthly) by the American

Physiological Society, 9650 Rockville Pike, Bethesda MD 20814-3991. Copyright @ 2005 by the American Physiological Society. ISSN: 0363-6119, ESSN: 1522-1490. Visit our website at http://www.the-aps.org/. 


\title{
Uterine motor alterations and estrous cycle disturbances
}

\section{associated with colonic inflammation in the rat}

\author{
Eric Houdeau, Muriel Larauche, Régine Monnerie, Lionel Bueno, and Jean Fioramonti \\ Neuro-Gastroenterology and Nutrition Unit, Institut National \\ de la Recherche Agronomique, Toulouse, France
}

Submitted 20 July 2004; accepted in final form 4 November 2004

\begin{abstract}
Houdeau, Eric, Muriel Larauche, Régine Monnerie, Lionel Bueno, and Jean Fioramonti. Uterine motor alterations and estrous cycle disturbances associated with colonic inflammation in the rat. Am J Physiol Regul Integr Comp Physiol 288: R630-R637, 2005. First published November 11, 2004; doi:10.1152/ajpregu.00482.2004.The impact of colitis on uterine contractility and estrous cycle was investigated after intracolonic administration of 2,4,6-trinitrobenzenesulfonic acid (TNBS) in rats. Colitis severity was assessed by macroscopic damage scoring (MDS) 4 days after TNBS, and myeloperoxidase (MPO) activity was measured in both colon and uterus of control and colitic rats. Estrous cycle stages were determined by vaginal smears and histology, and uterine contractility was assessed in vitro on longitudinal and circular strips. In control rats, uterine MPO activity varied markedly during the cycle and peaked around estrus. In rats with moderate colitis [MDS $<5,3.1 \pm 0.2$ (mean $\pm \mathrm{SE}$ )], uterine MPO decreased by $61 \%$ compared with estrus control, without disruption of the cycle. Frequency of spontaneous contractions was reduced by $32 \%$ in circular muscle. Contractile responses to $\mathrm{KCl}$ and carbachol were not affected, whereas maximal response to oxytocin decreased by $47 \%$ in the longitudinal muscle. In rats with severe colitis $(\mathrm{MDS}>5,6.0 \pm 0.2$ ), uterine MPO was reduced by $96 \%$ and estrous cycle was disrupted. Spontaneous contractility was impaired in circular strips, and a $39 \%$ decrease in the contraction frequency occurred in the longitudinal strips. Circular strips did not contract to $\mathrm{KCl}$ or carbachol; however, longitudinal strips had maximal responses to $\mathrm{KCl}$, carbachol, and oxytocin reduced by $36 \%, 27 \%$, and $46 \%$, respectively. Estrogen replacement protected the uterine responses to carbachol in colitic rats, whereas oxytocin responses remained depressed. These data indicate that colonic inflammation can influence both spontaneous and evoked uterine contractility, in relation to estrous cycle disturbances, impaired estradiol production, and functional alterations of myometrial cells.
\end{abstract}

colitis; female genital tract; oxytocin; acetylcholine; viscero-visceral interaction

IT IS WELL ACCEPTED THAT HORMONAL fluctuations across the menstrual cycle influence the gastrointestinal symptoms related to irritable bowel syndrome and inflammatory bowel diseases (IBD) $(15,22)$. Conversely, the impact of bowel pathology on the physiology of the female reproductive organs is poorly understood. Nonetheless, clinical observations have evidenced the occurrence of menstrual abnormalities (including amenorrhea, oligomenorrhea, and dysmenorrhea) and/or subfertility in active IBD patients, especially in those suffering from Crohn's disease $(2,7,21,49)$, suggesting a pathophysiological relationship.

In animal studies, viscero-visceral interactions involving both genital and gastrointestinal tracts have not been reported.

Address for reprint requests and other correspondence: E. Houdeau, INRA Neuro-Gastroenterology \& Nutrition Unit, 180 chemin de Tournefeuille BP3, F-31931 Toulouse Cedex 9, France (E-mail: houdeau@toulouse.inra.fr).
However, intestinal inflammatory processes involve the secretion of various inflammatory mediators with pleiotropic biological activities. For instance, a number of these substances are also physiologically produced in genital organs $(25,44)$. Indeed, animal and human studies show a pivotal role of proinflammatory mediators in the control of steroidogenesis and ovulation $(5,12)$ or in the initiation and the maintenance of uterine contractions at parturition $(25,27)$. Conversely, studies in the monkey and sheep indicate disturbances in steroidogenesis and ovarian cyclicity following endotoxin administration, considered as a model of systemic inflammation $(23,49,50)$. Furthermore, in vitro studies on myometrial cells have investigated the effects of proinflammatory mediators on oxytocin (OT) function, a potent uterotonic agent (39). These include an increase or a decrease of OT signaling and receptors, for shortand long-term exposures to inflammatory conditions, respectively $(35,42)$. However, these studies addressed the OT receptor function on cultured myometrial cells, but the uterine contractile responses to OT in inflamed animals remain to be investigated. From all of these data, one may hypothesize that a prolonged exposure of the genital tract to an inflamed area in the neighboring colon could affect ovarian and uterine functions.

The aim of the present study was therefore to investigate the effects of trinitrobenzenesulfonic acid (TNBS)-induced colitis on the ovarian cyclicity and uterine contractile activity in the rat. In view of a possible estrous cycle disruption during colitis, the complete achievement of the sexual cycle was assessed through daily vaginal smears and histological control of the uterus. The activity of the enzyme myeloperoxidase (MPO), an estimate of neutrophil infiltration, was measured in both the uterus and colon of control and colitic rats 1 ) to determine the tissue contents in neutrophils throughout the sexual cycle and 2) to highlight the putative modifications in the uterus following colonic inflammation. Both spontaneous and OT-evoked contractions were examined during the estrus period, where the uterus displays regular spontaneous contractions $(17,19)$ and high responsiveness to OT (28). Because the cholinergic innervation is an important regulatory mechanism of uterine activity $(17,41)$, the in vitro contractile response to carbachol (Carb), a muscarinic cholinergic agonist, was also studied.

\section{MATERIALS AND METHODS}

\section{Animal Preparation}

Experiments were performed on adult female Sprague-Dawley rats (Charles River, Saint-Aubin-Lès-Elbeuf, France), weighing 225-250 g. Rats were housed in groups of four per cage with free access to food

The costs of publication of this article were defrayed in part by the payment of page charges. The article must therefore be hereby marked "advertisement" in accordance with 18 U.S.C. Section 1734 solely to indicate this fact. 
and water, under a 12:12-h light-dark cycle, with lights on at 8:00 AM. In a first group of 40 rats, estrous cycle stages were assessed through daily vaginal smears (13), which were collected on glass slides and stained with Giemsa (Sigma, Saint-Quentin Fallavier, France). Ten rats in proestrus, estrus, metestrus, and diestrus stages were used for determination of basal MPO activity in the uterus and colon during the sexual cycle in healthy circumstances. In a second group of 70 rats in estrus, MPO activity in the uterus and colon $(n=$ $20)$ and uterine contractility $(n=50)$ were investigated after induction of the experimental colitis. A third group of 15 rats was bilaterally ovariectomized (OVX) under deep anesthesia with ketamine hydrochloride (150 mg/kg ip, Imalgène 500, Rhône Mérieux, Lyon, France). After a recovery period of 6 days, long enough to get a complete depletion of endogenous hormones, rats were reanesthetized and a Silastic capsule containing estradiol benzoate (EB) $(1,3,5$ [10]estratriene-3, 17 $\beta$-diol-3 benzoate; Sigma) was implanted under the skin of the neck. The EB implant (0.062 in. ID, 0.125 in. ID; Dow Corning, Midland, MI) was $10 \mathrm{~mm} / 100 \mathrm{~g}$ body wt to obtain physiological plasma levels of estradiol (46). All OVX + EB rats were used for evaluation of uterine contractility following experimental-induced colitis. All protocols were performed in compliance with the European laws on the protection of animals (86/609/EEC) and approved by the local institutional animal care and use committee.

\section{Inflammation Procedure}

To induce inflammation in the distal colon, rats were anesthetized with ketamine hydrochloride as above, and a volume of $0.1 \mathrm{ml}$ of TNBS (Sigma; $40 \mathrm{mg} / \mathrm{kg}$ diluted in $50 \%$ ethanol) was instilled into the lumen of the colon by use of a polyvinyl rubber catheter ( $2 \mathrm{~mm} \mathrm{OD}$ ) inserted rectally $7 \mathrm{~cm}$ proximal to the anus (30). Control rats received an equivalent volume of sterile saline because both ethanol and TNBS are inflammatory agents (20). Animals were killed by cervical dislocation 4 days after TNBS or saline treatments. In cyclic rats, all instillations were carried out at the estrus stage; thus they were killed 4 days later, i.e., on the estrus day of the following cycle, since a complete sexual cycle lasts $\sim 4$ days in the rat $(13,19)$.

\section{Macroscopic Damage Scores}

After death, the scoring of colonic macroscopic damage was done according to the method of Wallace et al. (47), although slightly modified. Briefly, the presence of mucosal hyperemia and of bowel wall thickening, the severity and extent of ulceration and tissue adhesion, as well as the occurrence of diarrhea, were rated according to a macroscopic damage score (MDS), ranging from 0 (normal appearance) to 13 (severe lesions) as previously described (30).

\section{MPO Activity}

The activity of the enzyme MPO, a marker of polymorphonuclear neutrophil primary granules, was determined in colonic and uterine tissues, according to a modified method of Bradley et al. (6). Segments of colon and uterine horns $(\sim 0.5 \mathrm{~cm}$ each) were suspended in potassium phosphate buffer (KPB; $50 \mathrm{mM}, \mathrm{pH}$ 6.0) and homogenized on ice with a Polytron. Three cycles of freezing and thawing were done, and suspensions were then centrifuged at 13,000 rpm for $15 \mathrm{~min}$ at $4^{\circ} \mathrm{C}$. Supernatants were discarded, and pellets were resuspended in the detergent hexadecyltrimethylammonium bromide buffer $(0.5 \%$, in KPB; Sigma) to release MPO from the primary granules. After sonication on ice, suspensions were centrifuged at 13,000 rpm for 15 min at $4{ }^{\circ} \mathrm{C}$, and supernatants were assayed spectrophotometrically for MPO activity and protein content.

Supernatants were diluted in KPB containing $0.167 \mathrm{mg} / \mathrm{ml}$ of $O$-dianisidine dihydrochloride and $0.0005 \%$ of hydrogen peroxide. Absorbance at $450 \mathrm{~nm}$ was recorded with Uvikon 860 spectrophotometer (Kontron Instruments, Saint Quentin en Yvelines, France) at 10 -s intervals over $2 \mathrm{~min}$. MPO of human neutrophils $(0.1 \mathrm{U} / 100 \mu \mathrm{l})$ was used as a standard. The absorbance change at $450 \mathrm{~nm}$ for $1 \mu \mathrm{mol}$ hydrogen peroxide/min at $25^{\circ} \mathrm{C}$ was calculated from the standard curve and equals 1 unit of MPO activity. Protein concentrations were determined by the method of Lowry (Bio-Rad detergent compatible protein assay, Bio-Rad, Ivry, France), and MPO activity was expressed as MPO units per gram of protein.

\section{Histology}

Uterine segments ( $1 \mathrm{~cm}$ length), excised from miduterine horn in cyclic rats of the control and inflamed groups, were fixed in Bouin's solution, cleared in xylene, and embedded in paraffin. Transverse tissue sections $(5 \mu \mathrm{m})$ were processed for routine histological analysis with hematoxylin and eosin staining.

\section{In Vitro Contractility}

Uterine strips (4 mm long) were prepared from miduterine horns of inflamed and control rats. Tissues were mounted in organ bath of Krebs solution (in mM: 2.8 glucose, $6.2 \mathrm{KCl}, 144 \mathrm{NaCl}, 2.5 \mathrm{CaCl}_{2}$, $0.5 \mathrm{MgSO}_{4}, 1 \mathrm{NaH}_{2} \mathrm{PO}_{4}$, and $30 \mathrm{NaHCO}_{3}$ ) at $30^{\circ} \mathrm{C}$, continuously bubbled with $95 \%-\mathrm{O}_{2}-5 \% \mathrm{CO}_{2}$. Depending on the orientation of the uterine strips in the organ bath, we measured isometric contractions of longitudinal muscle or circular muscle using a Bioscience UF1 tension transducer (Phymep, Paris, France) under $0.5 \mathrm{~g}$ resting force. A 45-min equilibration period was allowed before experiments. In a first group of cyclic rats instilled with saline $(n=7)$ or TNBS $(n=10)$, longitudinal and circular uterine strips were exposed to a $40 \mathrm{mM}$ $\mathrm{KCl}$-induced depolarization, considered as producing the maximal contraction of the uterine musculature (33). In all other animals, mechanical responses to cumulative doses of Carb $\left(10^{-8} \mathrm{M}\right.$ to $10^{-4}$ M) (carbamylcholine chloride; Sigma) or OT $\left(10^{-10} \mathrm{M}\right.$ to $10^{-5} \mathrm{M}$; Sigma) applied every 3 min were examined in each tissue preparation. Concentration-response curves were constructed by computerized calculation of the integral under the tension-time curve for $3 \mathrm{~min}$. Isometric changes in tissue tension and maximal effects $\left(E_{\max }\right)$ were expressed as a percentage above the spontaneous activity in the absence of drugs, or in grams per milligram of tissue over resting force, and potency as $\mathrm{EC}_{50}(\mu \mathrm{M})$.

\section{Data Analysis}

Data are expressed as means \pm SE. Differences in MPO activity in the uterus and colon throughout the estrous cycle were assessed by one-way ANOVA followed by Bonferroni posttest. Differences in $\mathrm{MPO}$ activity, and in $E_{\max }$ and $\mathrm{EC}_{50}$ values from concentrationresponse curves between the two groups, were tested using two-tailed Student's $t$-test for unpaired data. Statistical analyses were performed by running Prism 4 software (GraphPad, San Diego, CA). A $P<0.05$ was considered significant.

\section{RESULTS}

\section{MPO Activity in the Uterus and Colon Throughout the Estrous Cycle}

MPO activity in the uterus varied significantly throughout the cycle (range 2,932 \pm 575 to $7,558 \pm 1,335 \mathrm{U} / \mathrm{g}$ of protein; $n=10$ per stage), with the highest values measured in proestrus and estrus stages (Fig. 1A). No significant change was observed from proestrus to estrus, whereas MPO activity decreased significantly in metestrus and diestrus $(P<0.01$ and $P<0.05$ compared with proestrus, respectively). In the colon from the same cyclic rats, the basal MPO activity did not significantly vary from proestrus to diestrus stage (Fig. 1B). 
A

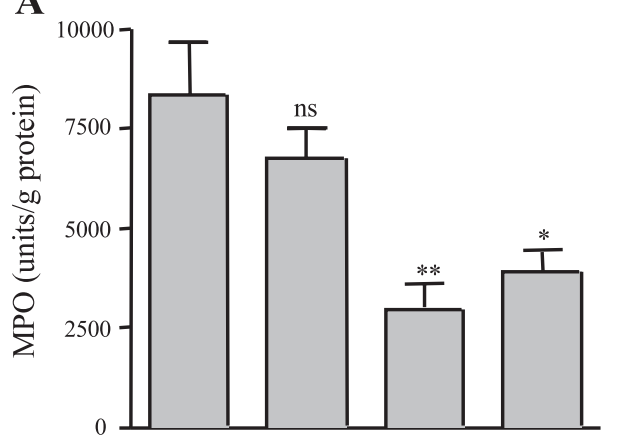

B

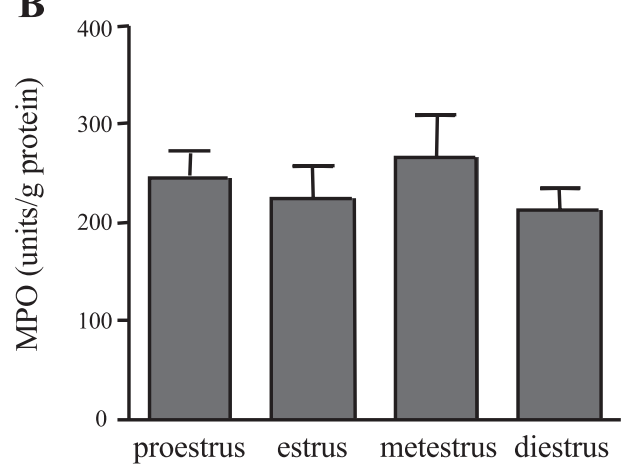

Fig. 1. Variation of myeloperoxidase (MPO) activity in the uterus $(A)$ and colon $(B)$ from proestrus to diestrus stages of the sexual cycle in healthy rats. Values are means $\pm \mathrm{SE} ; n=10 . * P<0.05, * * P<0.01$, and ns (not significant) vs. proestrus stage.

\section{Effect of TNBS-Induced Colitis on Estrous Cycle}

Macroscopic colonic damages and estrous cycle stages. Four days after intrarectal administration of saline to estrus rats, no alteration of the colonic mucosa was noted $(n=28)$. Rats instilled with saline were in estrus stage of the next sexual cycle, as revealed by the presence of only large keratinized cells on vaginal smears (not shown). In contrast, $52.4 \%(n=$ 22) of rats instilled with TNBS did not display estrus stage 4 days after treatment but displayed a persistent luteal phase. In these animals, the macroscopic colonic damage consisted of several inflammation sites with ulcerations in an area extending from 1 to $3 \mathrm{~cm}$ around the instillation point. Necrotic areas were often observed throughout the inflamed colonic region, with liquid feces in the colon, corresponding to a MDS of $6.0 \pm 0.2$ (range of 5-9). The remaining animals instilled with TNBS $(n=20)$ displayed estrus stages on vaginal smears and showed local hyperemia in the colon and/or bowel wall thickening without ulcers or diarrhea, corresponding to a MDS of $3.1 \pm 0.2$ (range of $1-4$ ).

Uterine histology. The uterine horn of control estrus rats exhibited a thick muscular wall, composed of an outer longitudinal and inner circular myometrial layer, and vascular bed between the two layers (Fig. 2A). The endometrium revealed numerous endometrial glands, with a thick epithelium composed of columnar cells exhibiting elongated nuclei, whereas the uterine lumen displayed complex and deep invaginations within the endometrial stroma. No morphological changes were observed in TNBS-treated rats displaying a MDS $<5$ in the colon (Fig. 2B). In contrast, animals with a MDS $>5$ showed a decrease of the diameter of the uterine horn, reduced endometrial stroma, and hypotrophy of the epithelium, with general loss of invaginations (Fig. 2C).

Colonic and uterine MPO activities. In basal conditions, MPO activities in the colon and uterus from estrus rats instilled with saline were $199 \pm 50$ and 7,240 $\pm 1,310 \mathrm{U} / \mathrm{g}$ of protein, respectively. TNBS instillation increased colonic MPO activity in all treated rats (Fig. $3 A$ ), and this increase was significantly higher $(P<0.05)$ in rats with a MDS $>5$ compared with animals with a MDS $<5(2,990 \pm 613$ vs. $914 \pm 52 \mathrm{U} / \mathrm{g}$ of protein). Conversely, the MPO activity was significantly decreased in the uterus from the same inflamed rats (Fig. $3 B$ ), by $61 \%$ in rats with a MDS $<5(2,800 \pm 336 \mathrm{U} / \mathrm{g}$ of protein; $P<$ 0.05 compared with control), and was nearly suppressed $(-96 \%)$ when a MDS $>5$ was scored in the colon $(258 \pm 70$ $\mathrm{U} / \mathrm{g}$ of protein; $P<0.01$ compared with control).

\section{Effects of TNBS-Induced Colitis on Uterine Contractility}

Spontaneous contractions. Four days after colonic instillation with saline, all uterine strips mounted in the organ bath
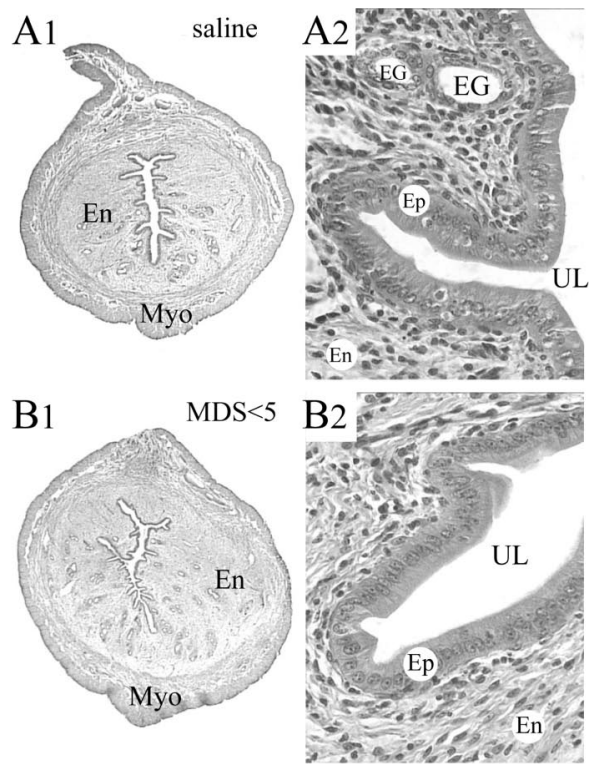

C1

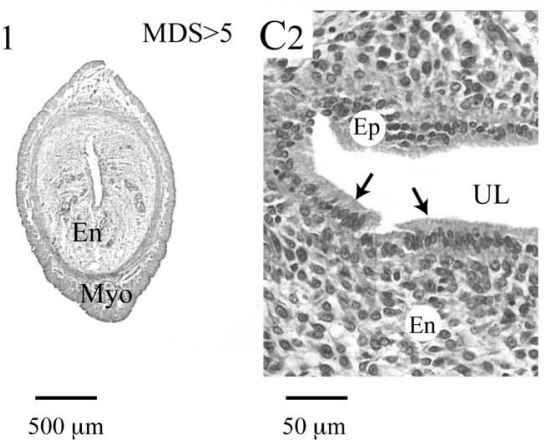

Fig. 2. Cross sections from the miduterine horn at low (A1-Cl) and high $(A 2-C 2)$ magnification obtained from control estrus rats treated with saline $(A)$ and rats 4 days after intracolonic administration of trinitrobenzenesulfonic acid (TNBS) and showing moderate (MDS $<5 ; B$ ) or severe colon damage (MDS $>5 ; C$ ). The development of endometrium (En) and the thickness of myometrium (Myo) were reduced during severe colitis only $(C)$ compared with control uterine horn $(A)$. Note the decrease in diameter of the uterine horn $(C 1)$ and general hypotrophy of epithelial cells (Ep; arrows in $C 2$ ) in rats displaying severe colon damage. Micrographs in each column are at the same final magnification. MDS, macroscopic damage score in the colon; UL, uterine lumen; EG, endometrial glands. 
A

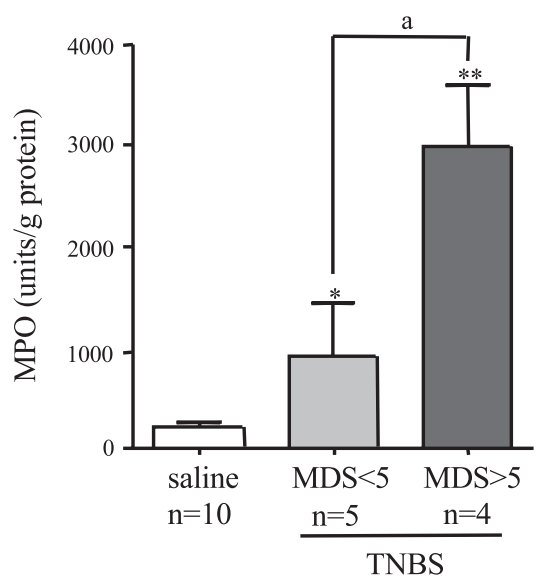

B

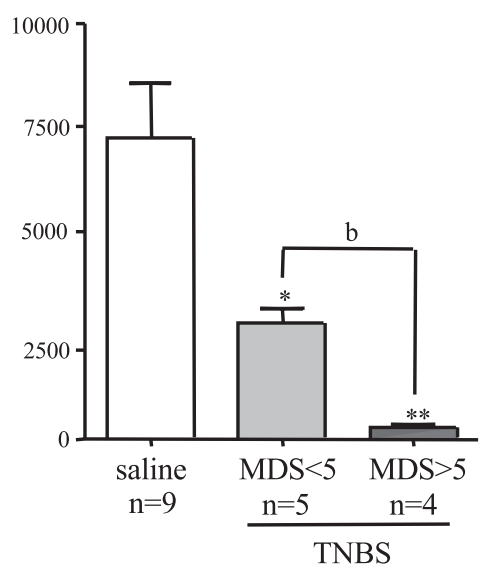

Fig. 3. Effect of TNBS-induced colitis on MPO activity in the colon $(A)$ and uterus $(B)$ of rats showing moderate (MDS $<5$ ) or severe (MDS $>5$ ) colon damage. Values are means \pm SE; $n$, no, of rats. $* P<0.05$ and $* * P<0.01$, significantly different from the corresponding saline control. Differences between groups: ${ }^{\text {a }} P<$ 0.05 and ${ }^{\mathrm{b}} P<0.001$. exhibited rhythmic spontaneous contractions. The frequency, amplitude, and duration of the contractions varied, depending on whether the recording was obtained from the longitudinal or the circular muscle layer (Fig. 4). The most distinctive difference occurred in the contraction frequency, with the highest occurring in the circular musculature (Table 1). In the TNBStreated group, rats characterized by moderate colonic damages (MDS $<5$ ) exhibited a significa'nt decrease in the frequency of uterine contractions $(-32 \%)$ in the circular muscle, whereas no change occurred in the longitudinal layer (Fig. 4, A2 and B2, and Table 1). A significant decrease $(-39 \%)$ in the frequency of contractions of the longitudinal muscle was observed only in rats with severe colonic injury (MDS > 5) (Fig. 4A3 and Table

A LM

A1

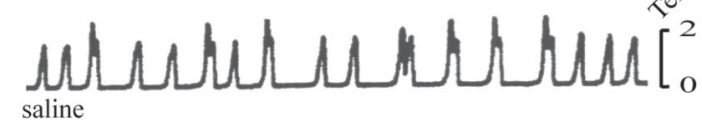

A2

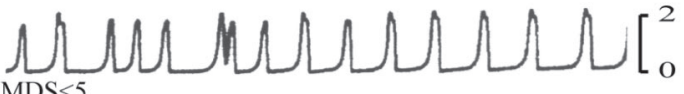

A3

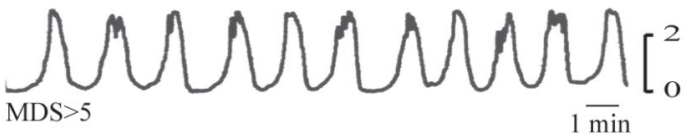

B

B1

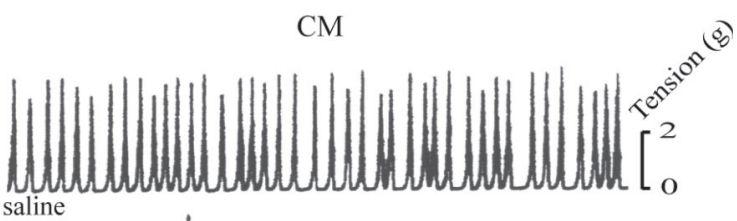

B2

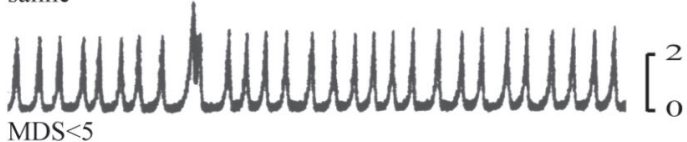

B3

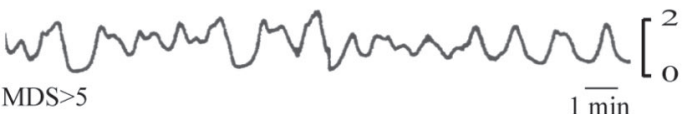

Fig. 4. Representative recordings of spontaneous contractions in the longitudinal $(\mathrm{LM} ; A)$ and circular $(\mathrm{CM} ; B)$ muscle layers of rat uterus 4 days after intracolonic instillation of saline ( $A 1$ and $B 1)$ or TNBS and showing moderate $(A 2$ and $B 2)$ or severe colon damage (A3 and $B 3)$.
1). In the same animals, the effects were more pronounced in the circular musculature, showing irregular tracing of spontaneous activity without rhythmic contractions (Fig. 4B3).

Uterine response to $\mathrm{KCl}$. Application of $\mathrm{KCl}$ induced nonreceptor-mediated contractions of the uterine strips, caused by a direct depolarization of the smooth muscle cells. In control animals, maximal contraction was obtained after $40 \mathrm{mM} \mathrm{KCl}$ application. Four days after intracolonic instillation of TNBS, in rats showing moderate colonic damage $(\mathrm{MDS}<5$ ), no differences were noticed in the contractile response to $40 \mathrm{mM}$ $\mathrm{KCl}$ compared with controls in either longitudinal or circular uterine strips (Fig. 5). In contrast, when severe colonic damage occurred $(\mathrm{MDS}>5)$, the response to $\mathrm{KCl}$ was significantly decreased $(-36 \%)$ in longitudinal strips (156 \pm 33 vs. $244 \pm$ $8 \%$ in control; $P<0.01)$, whereas circular muscle preparations from the same TNBS-treated animals were unresponsive to $\mathrm{KCl}$ (Fig. 5).

Uterine response to Carb. Carb caused a concentrationdependent increase in contractile activity in both longitudinal and circular muscle strips from control rats (Fig. 6), with a mean $\mathrm{EC}_{50}$ of $3.7 \pm 0.4 \mu \mathrm{M}$ in the longitudinal and $2.4 \pm 0.5$ $\mu \mathrm{M}$ in the circular strips, and $E_{\max }$ was obtained at $100 \mu \mathrm{M}$ in both muscle layers. TNBS-treated rats with a MDS $<5$ in the colon showed no significant difference in the contractile response to Carb in either longitudinal or circular strips when compared with controls (Fig. 6, $A$ and $B$ ). In contrast, in rats with severe colonic damages $(\mathrm{MDS}>5)$, the $E_{\max }$ in longitudinal uterine strips was significantly decreased by $27 \%$ compared with control value $(163 \pm 12$ vs. $222 \pm 16 \%, P<0.05)$,

Table 1. Frequency of spontaneous contractions in uterine muscle strips after intracolonic instillation of saline or TNBS

\begin{tabular}{llcc}
\hline \hline & \multicolumn{3}{c}{ Contraction Frequency, $\min ^{-1}$} \\
\cline { 2 - 4 } & \multicolumn{1}{c}{ Saline } & \multicolumn{1}{c}{ MDS $<5$} & MDS $>5$ \\
\hline LM & $1.00 \pm 0.08(n=14)$ & $0.95 \pm 0.09^{\text {ns }}(n=11)$ & $0.61 \pm 0.03 \ddagger(n=10)$ \\
CM & $1.47 \pm 0.11 *(n=16)$ & $1.00 \pm 0.18 \dagger(n=10)$ & ND $(n=10)$ \\
\hline
\end{tabular}

Values are means \pm SE from 3-4 replicates per rat; $n=$ no. of rats. MDS, macroscopic damage score in the colon; LM, longitudinal muscle; CM, circular muscle; ND, not determinable; TNBS, trinitrobenzenesulfonic acid. $* P<0.01$ vs. longitudinal muscle; $\uparrow P<0.05$ and $\ddagger P<0.001$ compared with respective saline control. ns, not significant. 


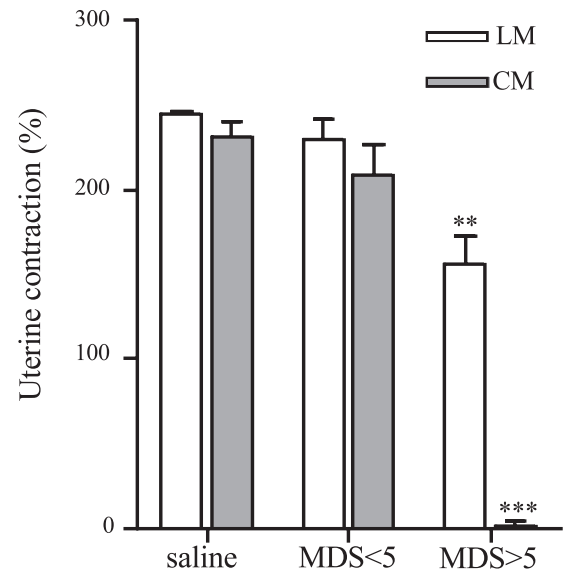

Fig. 5. Maximal contractile response to $\mathrm{KCl}(40 \mathrm{mM})$ of the $\mathrm{LM}$ and $\mathrm{CM}$ layers of rat uterus 4 days after intracolonic administration of saline or TNBS. Data are expressed as percentage above spontaneous activity $( \pm \mathrm{SE})$, and points are means of 4-8 replicates per animal in 5-7 rats per group. $* * P<$ 0.01 and $* * * P<0.001$ vs. corresponding saline control.

without affecting the $\mathrm{EC}_{50}(5.5 \pm 0.6 \mu \mathrm{M}, P>0.05)$ (Fig. $\left.6 A\right)$. Circular muscle preparations from the same animals did not respond to Carb (Fig. 6B).

Uterine response to $O T$. OT significantly increased contractions of longitudinal strips, whereas the circular preparations were less sensitive to OT stimulation (not shown). This is in agreement with the predominant localization of OT receptors in the longitudinal layer of myometrium (31). Thus all subsequent experiments with OT were conducted in the longitudinal musculature. In control rats, the $E_{\max }$ induced by OT was $269 \pm 20 \%$ and obtained at $100 \mathrm{nM}$ OT. In TNBS-treated rats, the maximal response to OT was markedly decreased (Fig. $6 C$ ), in a similar extent in animals with either moderate or severe colonic lesions $(-47 \%$ and $-46 \%$, respectively; $P<$ 0.01 compared with control). In contrast, there was no difference in $\mathrm{EC}_{50}$ values between control $(2.1 \pm 0.5 \mathrm{nM})$ and TNBS-treated rats $(1.6 \pm 0.6$ and $3.6 \pm 0.8 \mathrm{nM}$ for low and high MDS, respectively).

\section{Influence of Estradiol on Uterine Responses to Carb and OT}

In OVX + EB rats, the uterine contractile response to Carb was assessed primarily in the circular muscle preparations, where changes in the muscarinic receptor stimulation were found to be the most pronounced in cyclic rats treated with TNBS (see Uterine response to OT). After equilibration, the circular strips in OVX+EB rats were characterized by an almost flat tracing of spontaneous activity or exhibited scarce and erratic contractions (not shown). Thus all subsequent analysis of isometric tension changes were expressed as increases over the basal tension and normalized per tissue weight. In OVX+EB rats instilled with TNBS (Fig. 7A), the maximal response to Carb was not affected whatsoever by the extent of colonic lesions $(0.20 \pm 0.01$ and $0.23 \pm 0.04 \mathrm{~g} / \mathrm{mg}$ of tissue in MDS $<5$ and MDS $>5$ groups, respectively) compared with saline-treated OVX $+\mathrm{EB}$ rats $(0.23 \pm 0.01$ $\mathrm{g} / \mathrm{mg}$ of tissue, $P>0.05)$ and did not differ from results observed in estrus animals treated with saline $(0.19 \pm 0.02$ $\mathrm{g} / \mathrm{mg}$ tissue, $P>0.05)$. In contrast, when the OT stimulation was tested in the same TNBS-treated animals (Fig. 7B), the EB treatment did not restore the maximal response in the longitudinal muscle layer $(0.22 \pm 0.02$ and $0.21 \pm 0.04 \mathrm{~g} / \mathrm{mg}$ of tissue in MDS $<5$ and MDS $>5$ groups, respectively), which was $\sim 45 \%$ lower than that observed in saline $\mathrm{OVX}+\mathrm{EB}$ rats $(0.38 \pm 0.04 \mathrm{~g} / \mathrm{mg}$ of tissue, $P<0.05)$ or estrus rats $(0.36 \pm$ $0.03 \mathrm{~g} / \mathrm{mg}$ of tissue, $P<0.05$ ).

\section{DISCUSSION}

The present study provides the first evidence in rats that colitis induces uterine motor alterations and estrous cycle disturbances. We also report that, 4 days after colonic instillation of a single dose of TNBS $(40 \mathrm{mg} / \mathrm{kg})$, a time course that permits the complete achievement of a sexual cycle in the rat (19), disruption of the cycle was only observed in rats showing severe tissue injuries in the colon. In considering that macroscopic damage in the colon varies between individuals from an inflamed area localized at the injection site to a necrosis affecting large regions in the distal colon, our study has
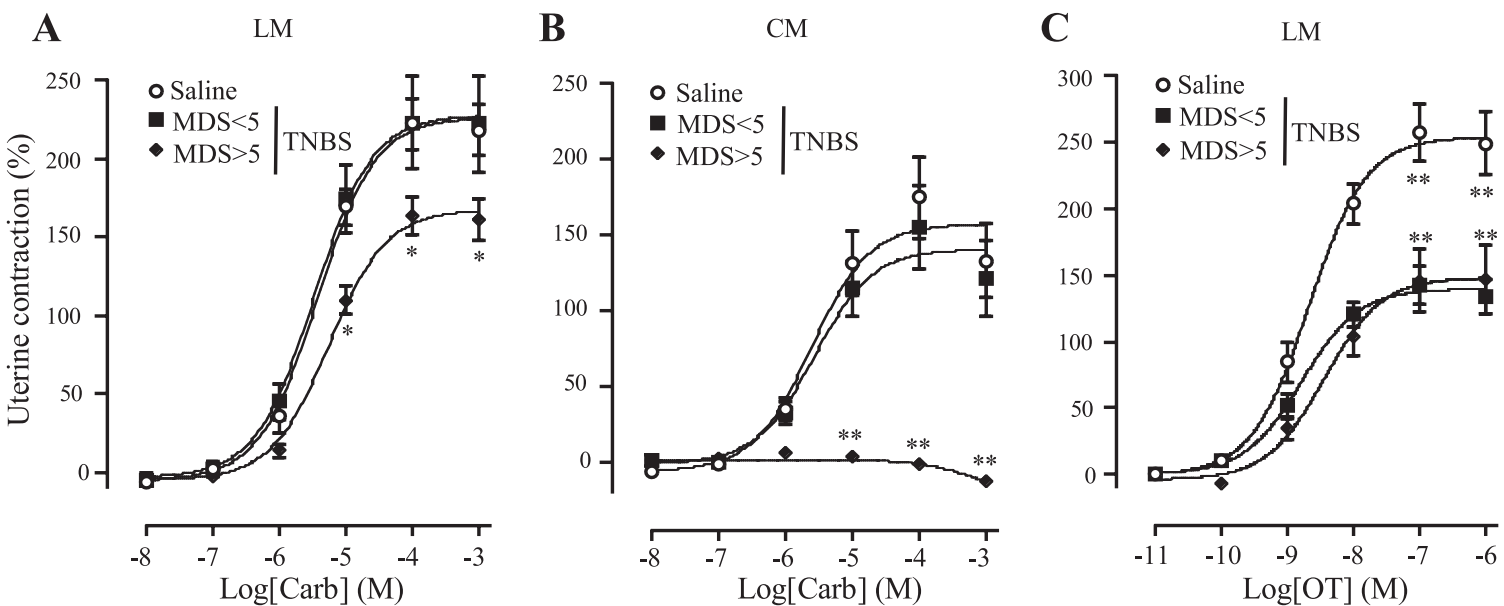

Fig. 6. Contractile activity of the CM and LM layers in response to increasing concentrations of carbachol (Carb; $A$ and $B)$ and oxytocin $($ OT; $C) 4$ days after intracolonic instillation of saline or TNBS. Data are expressed as percentage above spontaneous activity $( \pm \mathrm{SE})$, and points are means of $4-8$ replicates per animal in 6-8 rats per group. Brackets indicate concentration. $* P<0.05$ and $* * P<0.01$ vs. saline-treated control rats. 
A

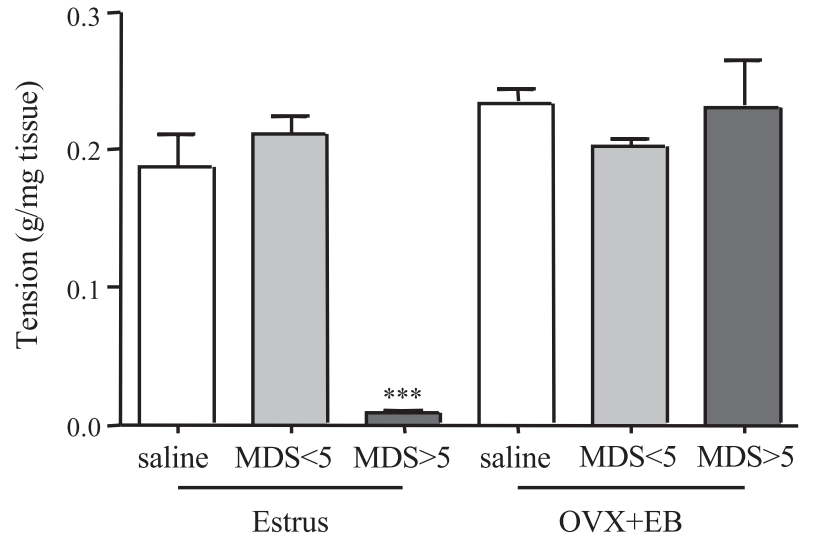

B

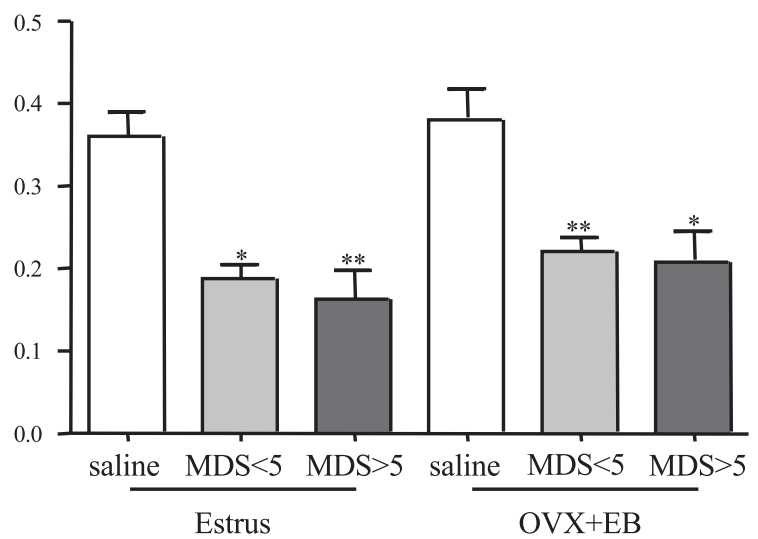

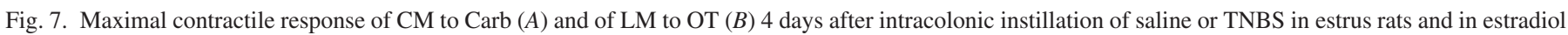

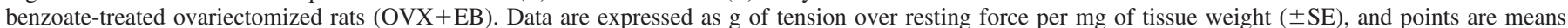
of 4-8 replicates per animal in $4-6$ rats per group. $* P<0.05, * * P<0.01$, and $* * * P<0.001$ vs. corresponding saline control.

investigated pathophysiological changes in the reproductive tract in relation to the severity of colonic inflammation.

Data concerning the increase of MPO activity in the colon after TNBS treatment reflect the mucosal infiltration of polymorphonuclear neutrophils in response to inflammation (30). The fact that colonic MPO activity peaked in rats with severe colitis emphasizes that the degree in neutrophil infiltration correlates well the magnitude of the inflammatory response. In comparison, the MPO activity measured in the uterus of colitic rats clearly demonstrated that no inflammatory response was initiated in the genital tract during colitis, regardless of the extent of tissue damage in the colon. This result eliminates the hypothesis of a systemic diffusion of TNBS, which could affect the neighboring organs in the pelvic/abdominal cavity. Conversely, we show that colitis induced a dramatic decrease in uterine MPO, compared with that shown in control estrus rats, reaching nadir in animals with severe colitis. In healthy individuals, it is of interest to note that uterine tissues exhibited high basal levels of MPO activity, reaching their maximum during the follicular phase of the cycle, i.e., at the proestrus and estrus stages. The elevated basal MPO in the uterus agrees with reports in rats and humans demonstrating that the uterine tissue remodeling throughout the cycle resembles an inflammatory response, with transient neutrophil infiltration $(24,40)$. Our observation that basal uterine MPO peaked during the follicular phase is consistent with the massive influx of neutrophils in this organ near estrus, due to a proinflammatory effect of estrogen $(24,45)$, the predominant hormone at this stage of the estrous cycle. In comparison, the present study also indicates that cyclic changes in ovarian steroids did not interfere with the basal MPO activity in the colon, demonstrating that colonic neutrophil populations in healthy conditions are insensitive to the steroid environment. The finding that colitis impairs the normal rise of uterine MPO in estrus indicates that the gut inflammatory response is able to block the cycle-dependent changes in uterine neutrophil populations. Moreover, we found that colitic rats exhibited a persistent luteal phase on vaginal smears in the case of severe inflammation, whereas histological findings on uteri revealed that the normal developmental sequence leading to an increase in the thickness of endometrium and luminal epithelium was impaired compared with healthy estrus rats. Together, these observations demonstrate that severe colonic inflammation disrupts the ovarian cyclicity and the associated uterine tissue remodeling. The mechanisms underlying this viscero-visceral interaction likely involve influence of inflammatory mediators on the ovarian steroidogenesis. Indeed, colon inflammation is associated with an increase in circulating cytokines, mainly IL- $1 \beta$, IL- 6 , IL- 8 , and TNF- $\alpha$ (14), although plasma levels of $\mathrm{TNF}-\alpha$ remain low in the rat model of TNBS-induced colitis (32). Studies in rats have shown that IL-1 $\beta$, which is produced in large amounts during acute colitis in rats and humans $(26,34)$, prevents the preovulatory increase in estradiol secretion and has cytotoxic effects on cultured ovarian cells $(12,18,38)$. Similar mechanisms for estrous cycle disruption have been reported in the ewe after endotoxin administration (23). In the present study, although estradiol levels were not measured, impairment of estradiol secretion is consistent with the inhibition of neutrophil accumulation and uterine tissue growth.

The in vitro uterine spontaneous contractility showed alterations that paralleled the severity of colitis, with marked differences between muscle layers. These alterations were characterized by a decreased contraction rate in the circular muscle during moderate inflammation, without changes in its longitudinal counterpart. In the longitudinal musculature, a similar alteration became evident only when the estrous cycle was impaired following severe colitis; the circular muscle, however, was unable to produce reproducible rhythmic contractions in the same animals. It is likely that these effects were closely related to ovarian cycle disturbances. Indeed, the spontaneous activity consists of myogenic contractions, with variable amplitude, duration, and frequency throughout the estrous cycle in relation to hormonal changes (19). From in vitro studies, we previously reported a higher contractile rate in uterine strips during the estrus compared with the diestrus stage (17). In the same study, we also showed that estrogen dominance mainly enhanced the contraction rate in the circular layer compared with the longitudinal layer, perhaps explaining why the circular muscle appeared more affected in colitic rats in the present report. Furthermore, the frequency of longitudinal 
muscle contractions during severe colitis was lowered to a level normally observed in diestrus stage of cyclic healthy rats $[0.61 \pm 0.03 \mathrm{contraction} / \mathrm{min}$ in the present study vs. $0.60 \pm$ 0.02 in diestrus (17)] with similar durations. This emphasizes that the motor pattern in this uterine musculature correlates well with the persistent luteal phase reported here when severe colitis occurred. Finally, the circular musculature was found unresponsive to $\mathrm{KCl}$ depolarization, whereas the longitudinal muscle was still able to contract, however, to a lesser extent than that observed in control estrus rats. The decreasing response to $\mathrm{KCl}$ depolarization was not unexpected, since estrogen plays a key role in promoting calcium uptake by myometrial cells (3), i.e., the second messenger of uterine contractility (44), that largely contributes for potassium depolarizationmediated contractions (4). Furthermore, it has been shown that induction of myometrial gap junctions, permitting the cell-tocell propagation of contractions (44), required high levels of estrogen (9), mainly in the circular muscle cells where gap junctions are more concentrated than in their longitudinal counterpart $(9,37)$.

When the myometrial response to Carb was examined, only rats with severe colitis revealed a defect in the contractile response to the muscarinic agonist. In line with $\mathrm{KCl}$ responses, the circular muscle was found to be unresponsive to Carb, and the longitudinal layer was even less affected, so that similar mechanisms for impaired $\mathrm{KCl}$ stimulation may also explain the altered Carb responses. Indeed, we have recently shown in cyclic rats that estrogen dominance at the estrus stage enhances myometrial sensitivity to muscarinic stimulation, whereas Carb was found to be ineffective in inducing contraction in diestrus, i.e., under progesterone dominance (17). Furthermore, estrogen enhances intracellular signaling pathways linked to activation of muscarinic receptors in rat myometrial cells (1), and we report here that estradiol replacement in OVX rats totally protected the muscarinic stimulation in animals subjected to severe colitis. Accordingly, the uterine muscarinic desensitization in our study appeared as a consequence of decreased levels of endogenous estradiol. In contrast, a decreased OT stimulation was observed in all TNBS-treated rats, i.e., whatever the extent of colon damage, indicating that these effects did not depend on the severity of colitis as for $\mathrm{KCl}$ and Carb. Moreover, estrogen treatment was found to be ineffective in restoring the uterine responses to OT, suggesting a distinct inhibition of this uterotonic pathway. For instance, decreased OT receptor density and impaired OT intracellular signaling have been recently demonstrated in cultured myometrial cells following a prolonged exposure to IL-1 $\beta$ and IL-6 $(16,35,36,42)$, even though controversial data exist regarding the deleterious effects of IL-6 on OT receptor expression $(16,42)$. Although OT receptor densities were not measured in our study, myometrial OT desensitization during colitis may involve similar processes, where increased levels of plasma IL- $1 \beta$ and IL-6 during colitis could result in an inhibition of the OT response of the uterus.

In summary, these data provide experimental evidence for pathophysiological relationships between digestive and reproductive tracts during colitis in the cyclic rat. This viscerovisceral interaction is able to disrupt the sexual cycle, as evidenced by the cascade of perturbations in endometrial and epithelial growth, neutrophil accumulation, and myometrial activity, both for the spontaneous and evoked contractions. On the basis of the protective effects of exogenous estrogen reported herein and because sex steroids regulate uterine growth and myometrial activity, it is likely that most of the perturbations elicited by colitis result from a defect in ovarian estradiol production, whereas alterations in uterine response to OT suggest a direct systemic action of proinflammatory mediators on OT receptor expression. Further studies are required to test this hypothesis. During the sexual cycle, myometrial contractions at the time of conception are essential for sperm transport toward the site of fertilization and later on for blastocyst implantation $(8,11,29)$. Moreover, the uterine tissue remodeling throughout the cycle is a key step in preparation toward gestation (10). Thus our findings in a rat model of colitis may have correlates in human IBD, for unexplained associations with ovarian dysfunction and reduced fertility, occurring mostly during active states of the disease $(7,48)$.

\section{ACKNOWLEDGMENTS}

We thank Christel Salvador-Cartier for technical assistance in histological analysis and H. Tiphaine for helpful discussions.

\section{REFERENCES}

1. Abdalla FMF, Abreu LC, and Porto CS. Effect of estrogen on intracellular signaling pathways linked to activation of M2- and M3-muscarinic acetylcholine receptors in the rat myometrium. Mol Cell Endocrinol 160: 17-24, 2000.

2. Alstead EM. Inflammatory bowel disease in pregnancy. Postgrad Med J 78: 23-26, 2002.

3. Batra S. Increase by oestrogen of calcium entry and calcium channel density in uterine smooth muscle. Br J Pharmacol 92: 389-392, 1987.

4. Batra $\mathbf{S}$ and Sjogren $\mathbf{C}$. Effects of estrogen treatment on calcium uptake by the rat uterine smooth muscle. Life Sci 24: 315-319, 1983.

5. Bonello N, McKie K, Jasper M, Andrew L, Ross N, Braybon E, Brannstrom M, and Norman RJ. Inhibition of nitric oxide: effects on interleukin-1 $\beta$-enhanced ovulation rate, steroid hormones, and ovarian leukocyte distribution at ovulation in the rat. Biol Reprod 54: 436-445, 1996.

6. Bradley PP, Priebat DA, Christensen RD, and Rothstein G. Measurement of cutaneous inflammation: estimation of neutrophil content with an enzyme marker. J Invest Dermatol 78: 206-209, 1982.

7. Bradley RJ and Rosen MP. Subfertility and gastrointestinal disease: "unexplained" is often undiagnosed. Obstet Gynecol Surv 59: 108-117, 2004.

8. Bulletti C, de Ziegler D, Polli V, Diotallevi L, Del Ferro E, and Flamigni C. Uterine contractility during the menstrual cycle. Hum Reprod 15, Suppl 1: 81-89, 2000.

9. Burghardt RC, Gaddy-Kurten D, Burghardt RL, Kurten RC, and Mitchell PA. Gap junction modulation in rat uterus. III. Structure-activity relationships of estrogen receptor-binding ligands on myometrial and serosal cells. Biol Reprod 36: 741-751, 1987.

10. Critchley HOD, Kelly RW, Brenner RM, and Baird DT. The endocrinology of menstruation-a role for the immune system. Clin Endocrinol (Oxf) 55: 701-710, 2001.

11. De Ziegler D, Bulletti C, Fanchin R, Epinay M, and Brioschi PA. Contractility of the nonpregnant uterus: the follicular phase. Ann NY Acad Sci 943: 172-184, 2001

12. Donesky BW, Dias de Moura M, Tedeschi C, Hurwitz A, Adashi EY, and Payne DW. Interleukin- $1 \beta$ inhibits steroidogenic bioactivity in cultured rat ovarian granulosa cells by stimulation of progesterone degradation and inhibition of estrogen formation. Biol Reprod 58: 1108-1116, 1998.

13. Everett JW. Progesterone and estrogen in the experimental control of ovulation time and other features of the estrous cycle in the rat. Endocrinology 43: 389-405, 1948.

14. Guimbaud R, Bertrand V, Chauvelot-Moachon L, Quartier G, Vidon N, Giroud JP, Couturier D, and Chaussade S. Network of inflammatory cytokines and correlation with disease activity in ulcerative colitis. Am J Gastroenterol 93: 2397-2404, 1998. 
15. Heitkemper MM, Cain KC, Jarrett ME, Burr RL, Hertig V, and Bond EF. Symptoms across the menstrual cycle in women with irritable bowel syndrome. Am J Gastroenterol 98: 420-430, 2003.

16. Helmer H, Tretzmuller U, Brunbauer M, Kaider A, Husslein P, and Knofler M. Production of oxytocin receptor and cytokines in primary uterine smooth muscle cells cultivated under inflammatory conditions. $J$ Soc Gynecol Investig 9: 15-21, 2002.

17. Houdeau E, Rossano B, and Prud'homme MJ. Regional and muscle layer variations in cholinergic nerve control of the rat myometrium during the oestrous cycle. Auton Neurosci 104: 1-9, 2003.

18. Hurwitz A, Hernadez ER, Payne DW, Dharmarajan AM, and Adashi EY. Interleukin-1 $\beta$ is both morphogenic and cytotoxic to cultured rat ovarian cells: obligatory role for heterologous, contact-independent cellcell interaction. Endocrinology 131: 1643-1649, 1992.

19. Ishikawa M and Fuchs AR. Electrical and mechanical activity of rat uterus in vivo during the estrous cycle. Am J Obstet Gynecol 132: 611-619, 1978.

20. Jacobson K, McHugh K, and Collins SM. Experimental colitis alters myenteric nerve function at inflamed and noninflamed sites in the rat. Gastroenterology 109: 718-722, 1995.

21. Kane S. Inflammatory bowel disease in pregnancy. Gastroenterol Clin North Am 32: 323-340, 2003.

22. Kane SV, Sable K, and Hanauer SB. The menstrual cycle and its effect on inflammatory bowel disease and irritable bowel syndrome: a prevalence study. Am J Gastroenterol 93: 1867-1872, 1998.

23. Karsch FJ and Battaglia DF. Mechanisms for endotoxin-induced disruption of ovarian cyclicity: observations in sheep. Reprod Suppl 59: 101-113, 2002.

24. Kaushic C, Frauendorf E, Rossoll RM, Richardson JM, and Wira CR. Influence of the estrous cycle on the presence and distribution of immune cells in the rat reproductive tract. Am J Reprod Immunol 39: 209-216, 1998.

25. Kelly RN. Inflammatory mediators and parturition. Rev Reprod 3: 89-96, 1996.

26. Khan I and al-Awadi FM. Colonic muscle enhances the production of interleukin-1 $\beta$ messenger RNA in experimental colitis. Gut 40: 307-12, 1997.

27. Khatun S, Kanayama N, Belayet H, Yonezawa M, Kobayashi T, and Terao T. Interleukin- 8 potentiates the effect of interleukin-1-induced uterine contractions. Hum Reprod 14: 560-565, 1999.

28. Lefebvre DL, Farookhi R, Larcher A, Neculcea J, and Zingg HH. Uterine oxytocin gene expression. I. Induction during pseudopregnancy and the estrous cycle. Endocrinology 134: 2556-2561, 1994.

29. Leyendecker G, Kunz G, Wildt L, Beil D, and Deininger H. Uterine hyperperistalsis and dysperistalsis as dysfunctions of the mechanism of rapid sperm transport in patients with endometriosis and infertility. Hum Reprod 11: 1542-1551, 1996.

30. Mazelin L, Theodorou V, Fioramonti J, and Bueno L. Vagally dependent protective action of calcitonin gene-related peptide on colitis. Peptides 20: 1367-1374, 1999.

31. Mhaouty-Kodja S, Houdeau E, and Legrand C. Regulation of myometrial phospholipase $\mathrm{C}$ system and uterine contraction by $\beta$-adrenergic receptors in midpregnant rat. Biol Reprod 70: 570-576, 2004.

32. Neilly PJ, Gardiner KR, Kirk SJ, Jennings G, Anderson NH, Elia M, and Rowlands BJ. Endotoxaemia and cytokine production in experimental colitis. Br J Surg 82: 1479-1482, 1995.
33. Niiro N, Nishimura J, Hirano K, Nakano H, and Kanaide H. Mechanisms of galanin-induced contraction in the rat myometrium. Br J Pharmacol 124: 1623-1632, 1998.

34. Rachmilewitz D, Simon PL, Schwartz LW, Griswold DE, Fondacaro JD, and Wasserman MA. Inflammatory mediators of experimental colitis in rats. Gastroenterology 97: 326-337, 1989.

35. Rauk PN and Chiao JP. Oxytocin signaling in human myometrium is impaired by prolonged exposure to interleukin-1. Biol Reprod 63: 846$850,2000$.

36. Rauk PN and Friebe-Hoffmann U. Interleukin-1 $\beta$ down-regulates the oxytocin receptor in cultured uterine smooth muscle cells. Am J Reprod Immunol 43: 85-91, 2000.

37. Risek B, Klier G, Phillips A, Han DW, and Gilula NB. Gap junction regulation in the uterus and ovaries of immature rats by estrogen and progesterone. J Cell Sci 108: 1017-1032, 1995.

38. Rivest $\mathbf{S}$ and Rivier C. Interleukin-1 $\beta$ inhibits the endogenous expression of the early gene c-fos located within the nucleus of LH-RH neurons and interferes with hypothalamic LH-RH release during proestrus in the rat. Brain Res 613: 132-142, 1993.

39. Russell JA, Leng G, and Douglas AJ. The magnocellular oxytocin system, the fount of maternity: adaptations in pregnancy. Front Neuroendocrinol 24: 27-61, 2003.

40. Salamonsen LA, Zhang J, and Brasted M. Leukocytes networks and human endometrial remodelling. J Reprod Immunol 57: 95-108, 2002.

41. Sato S, Hayashi RH, and Garfield RE. Mechanical responses of the rat uterus, cervix, and bladder to stimulation of hypogastric and pelvic nerves in vivo. Biol Reprod 40: 209-219, 1989.

42. Schmid B, Wong S, and Mitchell BF. Transcriptional regulation of oxytocin receptor by interleukin-1 $\beta$ and interleukin-6. Endocrinology 142: 1380-1385, 2001.

43. Sharkey A. Cytokines and implantation. Rev Reprod 3: 52-61, 1998.

44. Tabb TN and Garfield RE. Molecular biology of uterine contractility. Clin Obstet Gynecol 35: 494-504, 1992.

45. Tibbetts TA, SheConneely OM, and O'Malley BW. Progesterone via its receptor antagonizes the pro-inflammatory activity of estrogen in the mouse uterus. Biol Reprod 60: 1158-1165, 1999.

46. Vongher JM and Frye CA. Progesterone in conjunction with estradiol has neuroprotective effects in an animal model of neurodegeneration. Pharmacol Biochem Behav 64: 777-785, 1999.

47. Wallace JL, Keenan CM, Gale D, and Shoupe TS. Exacerbation of experimental colitis by nonsteroidal anti-inflammatory drugs is not related to elevated leukotriene B4 synthesis. Gastroenterology 102: 18-27, 1992.

48. Weber AM, Ziegler C, Belinson JL, Mitchinson AR, Widrich T, and Fazio V. Gynecologic history of women with inflammatory bowel disease. Obstet Gynecol 86: 843-847, 1995.

49. Xiao E, Xia-Zhang L, and Ferin M. Stress and the menstrual cycle: relevance of cycle quality in the short- and long-term response to a 5-day endotoxin challenge during the follicular phase in the rhesus monkey. J Clin Endocrinol Metab 83: 2454-2460, 1998.

50. Xiao E, Xia-Zhang L, and Ferin M. Stress and the menstrual cycle: short- and long-term response to a 5-day endotoxin challenge during the luteal phase in the rhesus monkey. J Clin Endocrinol Metab 84: 623-626, 1999. 